\title{
"APRENDI A PENSAR QUE MÚSICA TAMBÉM É HISTÓRIA" A CANÇÃO VAI À ESCOLA: PERSPECTIVAS DA EDUCAÇÃO HISTÓRICA
}

\section{"LEARNED TO THINK THAT IS ALSO MUSIC HISTORY" THE SONG GOES TO SCHOOL: PERSPECTIVES OF HISTORICAL EDUCATION}

Luciano de Azambuja ${ }^{1}$

Maria Auxiliadora Schmidt ${ }^{2}$

RESUMO: Apresenta os resultados de uma pesquisa junto aos jovens alunos do Ensino Médio de uma escola de Curitiba (Paraná). A partir da Educação Histórica como campo de investigação, vê as protonarrativas destes alunos quanto à questão da música na sua articulação coma a História. Mais precisamente sobre a música como fonte documental e sua utilização na construção do aprendizado histórico.

Palavras-chave: Educação Histórica. Canção. Protonarrativas.

ABSTRACT: Presents the results of a survey of young high school students from a school in Curitiba (Paraná). From the Historical Education as a field of research, see the protonarrative these students on the issue of music in its articulation coma history. More precisely about music as source material and its use in the construction of learning history.

Keywords: Historical Education. Song. Protonarrative.

${ }^{1}$ Instituto Federal de Santa Catarina, Universidade Federal do Paraná.

${ }^{2}$ Universidade Federal do Paraná. 


\section{Introdução}

A Educação Histórica tem como ponto de vista privilegiado a cognição histórica situada, entendida como a aprendizagem histórica "situada na ciência da História" (SCHMIDT, 2009, p. 30), cujo conhecimento é construído em função das experiências pessoais dos sujeitos nos "contextos concretos em que os alunos utilizam as suas experiências para dar sentido a um passado que sempre se ajusta às suas idéias prévias" (BARCA, 2005, p. 19). Nessa linha de raciocínio, a cognição histórica situada circunscreve-se nos fundamentos epistemológicos da Ciência da História e nas situações específicas em que sujeitos específicos estabelecem em relações de ensino e aprendizagem em História. Seu objeto principal é a investigação das situações e relações de ensino e aprendizagem histórica; as relações que alunos e professores estabelecem com o conhecimento histórico e que contribuam para a formação da consciência histórica dos sujeitos envolvidos.

O ponto de partida de uma pesquisa em Educação Histórica são as protonarrativas (RÜSEN, 2001, p. 76) das crianças, jovens e adultos, enfim, dos sujeitos investigados. Nessa perspectiva, o agir humano passado sempre está presente no agir humano presente, em uma espécie de "pré-história" (não no sentido cronológico, mas na perspectiva de um pressuposto) que antecede o trabalho de interpretação da consciência histórica. Em outras palavras, a consciência histórica constitui-se na vida prática, nos feitos humanos que sempre sintetizam originariamente a experiência do passado e a expectativa do futuro, no sentido de uma orientação no tempo. Uma intervenção transformadora da qualidade da aprendizagem histórica demanda um conhecimento sistemático das ideias históricas dos alunos por parte dos professores, pois "não podemos modificar aquilo que não conhecemos" (LEE apud BARCA, 2009, p.60). O jovem quando vai à escola não deixa de ser jovem; carrega consigo, além de sua pesada mochila, suas ideias, concepções e pontos de vista, suas múltiplas identidades juvenis que se constituem em 
suas respectivas vidas práticas e que não devem ser ignoradas, menosprezadas e consideradas um entrave ou obstáculo à aprendizagem. Ao contrário, é justamente esse senso comum dos jovens alunos que deve ser incorporado como ponto de partida e pressuposto metodológico para a constituição, formação e progressão da consciência histórica.

As ideias históricas de jovens alunos são construídas a partir das concepções advindas da experiência social cotidiana, portanto, o conceito histórico deve ser significativo para quem os vai aprender. Os conceitos são históricos, não porque remetem ao passado, mas porque lidam com a relação intrínseca que existe entre a lembrança do passado e a expectativa do futuro, no quadro de orientação da vida prática presente (RÜSEN, 2007, p. 92). Rüsen dialeticamente, primeiro distingue e opõe conceitos históricos em nomes próprios e categorias históricas, para depois sintetizá-los em um conceito mais amplo, que visa a uma interpretação de fatos concretos ocorridos da sucessão do tempo. Nessa mesma perspectiva, mas com designações diferentes, Peter Lee distingue conceitos substantivos e conceitos de segunda ordem. Nessa linha de raciocínio, e como veremos adiante, Judaísmo, Cristianismo, Islamismo, Nazismo e outros "conteúdos históricos", constituem conceitos históricos ou conceitos substantivos; por outro lado, fonte histórica, narrativa histórica e consciência histórica, são categorias históricas ou conceitos de segunda ordem; são categorias específicas da epistemologia da Ciência da História. Mas se observarmos atentamente, como aponta Rüsen, podemos compreender que conceitos históricos e categorias históricas são intrínsecos e indissociáveis: como dois lados de uma mesma moeda, quando põe-se a girar, cada lado contribui para a finalidade última de interpretação e orientação da experiência humana no tempo.

O estudo exploratório foi realizado no segundo semestre de 2010, em uma escola pública de Curitiba-PR, tendo como público alvo alunos do ensino médio e contou com a participação de 08 estagiários da disciplina Prática de Ensino e Estágio Supervisionado em História no Ensino Médio. Na perspectiva da Educação Histórica, a proposta da disciplina de Prática de Ensino e Estágio 
Supervisionado teve como principais objetivos: consolidar o princípio de formação inicial do professor de História como professor-investigador; aproximar e relacionar a cultura escolar com a cultura juvenil dos jovens alunos investigados; e operacionalizar um projeto de Prática de Docência a partir das leituras e escutas de uma canção popular apropriada enquanto fonte histórica no processo de ensino, aprendizagem e formação da consciência histórica de jovens alunos do ensino médio.

\section{Perspectivas Teóricas}

Delimitada a escola e o público alvo, a primeira etapa da disciplina foi constituída de estudos teóricos por meio da seleção, leitura e discussão de textos disponibilizados aos alunos estagiários. Em um primeiro momento, foram debatidos os textos, La experiencia liceísta, de François Dubet e Danilo Martuccelli, e $A$ invisibilidade da juventude na vida escolar, de Luiza Mitiko Yshiguro Camacho. De Dubet e Martucelli, destacou-se o princípio de integração ou socialização que delimita a construção da experiência dos alunos da escola elementar. A experiência dos alunos do ensino médio se processa de uma forma mais complexa e heterogênea em torno de uma tensão entre a lógica de subjetivação adolescente e a manutenção de um conformismo escolar e familiar. É nessa situação em que o indivíduo, ou emerge pleno da socialização escolar, ou ao contrário, frustra-se e desmotiva-se diante de sua incapacidade de integração à cultura escolar. Esses autores levantam as instigantes questões: em que medida a experiência juvenil é compatível com a vida escolar? Em que medida se pode "crescer na vida" estando preso à organização escolar? Como motivar-se quando nada do que é escolar interessa verdadeiramente? Como aproximar e relacionar a cultura escolar com as experiências vividas pelos seus jovens alunos, enfim, com as suas respectivas culturas juvenis? Estas questões, por sua vez, nortearam a pergunta de orientação do estudo exploratório realizado na proposta de Prática de Ensino: 
Como articular e relacionar cultura histórica escolar, cultura da escola, e cultura na escola?

Na mesma direção, Camacho partilha os resultados parciais da pesquisa intitulada $O$ jovem que há para além do aluno, na qual aborda o processo de identificação dos educandos por parte das instituições de ensino. Diante da invisibilidade da juventude na vida escolar, sugere que se olhe e veja o aluno além do aluno, mas antes e acima de tudo como um jovem: "A ideia de jovem é construída social e culturalmente e, portanto, muda conforme o contexto histórico, social, econômico e cultural. Não se pode conceber, pois, uma juventude, mas juventudes" (CAMACHO, 2004, p. 330). As diferentes situações e experiências dos sujeitos possibilitam a construção de diversas concepções de jovem e de juventude. Entretanto, a escola não vê o aluno como um jovem; a condição de jovem precede a condição de aluno; antes de ser aluno, o aluno é um jovem, um jovem aluno. A escola tem-se mostrado incapaz de construir relações com os interesses, expectativas e linguagens de seus jovens alunos, e por vezes, provoca rupturas muitas vezes irreversíveis, entre o mundo escolar e o mundo juvenil do aluno, ou seja, implode as pontes entre a cultura escolar e a cultura na escola. "O reconhecimento de que a condição de jovem precede a condição de aluno e de que ambas estão intimamente ligadas, poderia ser o primeiro passo dado pela escola em direção à visibilidade da juventude no espaço escolar e à transformação de seus alunos em jovens alunos" (CAMACHO, 2004, p. 340).

Em um segundo momento, para abordar a especificidade e a complexidade do objeto canção, foram discutidos dois textos de Marcos Napolitano: Para uma história cultural da música popular, e Aquarela do Brasil. No primeiro, Napolitano busca "um conjunto de problemas teóricometodológicos e sistematizar procedimentos básicos que orientem o pesquisador e que ele deve respeitar para realizar uma abordagem produtiva e instigante do documento-canção" (NAPOLITANO, 2002, p. 77). Apesar de sinalizar que 0 professor do ensino médio pode aproveitar alguns procedimentos para os usos da canção em sala de aula, o texto está mais 
focado na canção enquanto fonte para a pesquisa histórica, do que a canção como "recurso didático para o ensino de humanidades em geral". Napolitano alcança seus objetivos ao apresentar a sistematização de uma abordagem teórica e metodológica do "documento-canção", em toda sua complexidade e especificidade, com destaque para a indissociabilidade dos parâmetros poéticos e musicais, além da contextualização histórica do processo de criação, produção e recepção das obras. Conclui afirmando que a música popular e a música erudita, "constitui um grande conjunto de documentos históricos para se conhecer não apenas a história da música brasileira, mas a própria História do Brasil, em seus diversos aspectos" (NAPOLITANO, 2002, p.110). A leitura do outro texto encaminhado, Aquarela do Brasil, do livro Lendo Música: 10 ensaios sobre 10 canções, teve como principal objetivo observar como o autor operacionaliza a sua abordagem histórica da canção em um estudo de caso específico, procurando identificar as categorias de análise utilizadas.

Para concluir esse segundo momento, de estudos teóricos, foram apresentadas algumas contribuições da dissertação de mestrado em Literatura, intitulada Leitura, Canção e História: Mundo Livre s/a contra o Império do Mal, na qual procurou-se operacionalizar uma proposta de leitura histórica da canção em um estudo de caso específico. Definiu-se inicialmente canção popular enquanto produto de um conjunto indissociável constituído de palavra, a letra; música propriamente dita, melodia, harmonia, ritmo e timbre; a performance vocal, e por último, os aspectos técnicos, tecnológicos e mercadológicos de todo o processo que envolve a produção fonográfica (AZAMBUJA, 2007). A partir das referências dessa dissertação foi proposta uma determinada leitura histórica da canção, uma leitura em que a liberdade subjetiva do leitor-ouvinte, seja delimitada pela materialidade objetiva do suporte fonográfico, contextualizado na historicidade das condições de criação e produção do compositor-intérprete. Uma leitura que privilegie uma tripla abordagem histórica da canção: a história da canção, a história na canção e a canção na história. Nessa perspectiva, toda canção é histórica, produzida e recepcionada em determinado tempo e lugar; mas nem toda canção expressa 
uma temática especificamente histórica, e produz significados e efeitos duradouros sobre a história cultural de uma sociedade. Enfim, uma leitura que leve em conta a especificidade, complexidade e unicidade do objeto canção, apropriado enquanto fonte histórica para o ensino e aprendizagem de História.

Para costurar a articulação entre teoria e prática na disciplina de prática de ensino, tomou-se como referencial as ideias de Jörn Rüsen, particularmente as categorias: consciência histórica, narrativa histórica e fonte histórica. Consciência histórica, entendida como competência cognitiva de interpretação-orientação da experiência humana no tempo. A narrativa histórica constitui a consciência histórica por meio de uma relação entre experiência do passado, interpretação do presente e orientação do futuro, mediada por uma representação abrangente da continuidade, que organiza essa relação estrutural das três dimensões temporais; a consciência histórica se constitui e se expressa mediante o movimento da narrativa. Fontes históricas: o método é que transforma os resíduos em fontes para extrair as informações que ela própria não pode formular. A partir da costura e articulação dessas três categorias históricas é que passamos para o próximo passo do estudo exploratório: o caminho metodológico.

\section{Percurso Metodológico}

Finalizada a etapa de estudos teóricos, os alunos estagiários passaram a estabelecer os contatos com a escola e os professores que aceitaram participar da proposta de estágio. Os professores de História da escola pesquisada optaram livremente em participar ou não do estudo exploratório. Os oito alunos selecionados para a investigação fizeram o seu estágio em uma das turmas do primeiro, segundo e terceiro ano do ensino médio, abarcando um total de 189 alunos, meninos e meninas adolescentes com idade variando entre 14 e 17 anos. A distribuição dos alunos estagiários nas respectivas turmas foi da seguinte forma: Marina em uma turma do terceiro ano com 29 
alunos; Lígia em uma turma do segundo ano com 25 alunos; Luiza em uma amostra de uma turma do primeiro ano com 12 alunas; Rosa em uma turma do segundo ano com 31 alunos; Ana Júlia em uma turma do segundo ano com 33 alunos, Bárbara em uma turma do terceiro ano com 25 alunos; José em uma turma do segundo ano com 24 alunos; e João em uma amostra de uma turma do primeiro ano de 10 alunos.

\begin{tabular}{|c|c|c|c|c|}
\hline $\begin{array}{c}\text { ENSINO } \\
\text { MÉ́DIO / } \\
\text { SÉRIES }\end{array}$ & ALUNOS & MENINOS & MENINAS & IDADES \\
\hline $\begin{array}{c}\text { PRIMEIRO } \\
\text { ANO: 02 }\end{array}$ & 22 & 9 & 12 & 14 a 15 anos \\
\hline $\begin{array}{c}\text { SEGUNDO } \\
\text { ANO: 04 }\end{array}$ & 113 & 34 & 30 & 15 a 16 anos \\
\hline $\begin{array}{c}\text { TERCEIRO } \\
\text { ANO: 02 }\end{array}$ & 54 & $\mathbf{2 5}$ & $\mathbf{2 8}$ & $\mathbf{1 6}$ a 17 anos \\
\hline TOTAL: 08 & $\mathbf{1 8 9}$ & $\mathbf{6 8}$ & $\mathbf{7 0}$ & $\mathbf{1 4}$ a 17 anos \\
\hline PORCENTAGEM & $100 \%$ & $47 \%$ & $53 \%$ & $\begin{array}{l}\text { *05 alunos não } \\
\text { se identificaram } \\
\text { e/ou não } \\
\text { revelaram a } \\
\text { idade }\end{array}$ \\
\hline
\end{tabular}

\section{Quadro A: Turmas investigadas}

Foi orientado aos alunos estagiários que, no primeiro contato com a turma propusessem uma breve discussão sobre a importância da música na vida dos jovens, e encaminhassem uma investigação sobre os seus interesses e gostos musicais. Essa pesquisa revelou os seguintes dados: a grande maioria dos jovens alunos e alunas tem como gênero musical de preferência o rock, gênero que se desdobra em diversos estilos, tipos e tendências tais como heavy metal, hardcore, pop rock, rock'n roll, e outros como, alternativo, surf song e emo. 


\begin{tabular}{|l|c|}
\hline ROCK & 153 \\
\hline HEAVY METAL & 24 \\
\hline HARDCORE & 15 \\
\hline POP ROCK & 12 \\
\hline ROCK'N ROLL & 11 \\
\hline $\begin{array}{l}\text { OUTROS: ALTERNATIVO; SURF } \\
\text { SONG; EMO }\end{array}$ & 04 \\
\hline
\end{tabular}

Quadro B: música estrangeira (anglo-americana)

Também fizeram referência aos gêneros pop, música clássica, música eletrônica, rap, reggae, hip hop, funk, e jazz em percentuais decrescentes.

\begin{tabular}{|c|c|}
\hline POP & 70 \\
\hline $\begin{array}{c}\text { MÚSICA CLÁSSICA / } \\
\text { ERUDITA }\end{array}$ & 15 \\
\hline $\begin{array}{c}\text { MÚSICA ELETRÔNICA / } \\
\text { DANCE }\end{array}$ & 14 \\
\hline RAP & 13 \\
\hline REGGAE & 13 \\
\hline HIP HOP & 9 \\
\hline FUNK & 6 \\
\hline JAZZ & 02 \\
\hline
\end{tabular}

\section{Quadro C: Outros gêneros estrangeiros}

Observa-se o predomínio da música que intitulamos música estrangeira de tradição anglo-americana. Interessante constatar que uma pequena amostra de alunos que se autoidentificam com o gosto musical eclético, parece estabelecer a ponte entre a música estrangeira, e a música brasileira, assim designada por nós, pois o seu gosto diversificado e aberto permite gostar "de tudo um pouco".

Apesar do predomínio da música estrangeira anglo-americana, a música popular brasileira possui um lugar significativo nos gostos musicais dos jovens alunos investigados. Destacam-se os seguintes subgêneros em ordem de freqüência de citações: sertanejo, pagode, $m p b$, gospel, rock brasil, pop brasil, samba e outros como rap, reggae e funk; pode-se perceber que há uma 
série de gêneros estrangeiros que são abrasileirados e que constituem dicções que passam a fazer parte da música popular brasileira.

\begin{tabular}{|c|c|}
\hline MÚSICA POPULAR BRASILEIRA & 116 \\
\hline SERTANEJO & 34 \\
\hline PAGODE & 24 \\
\hline MPB & 22 \\
\hline GOSPEL & 16 \\
\hline ROCK BRASIL & 15 \\
\hline POP BRASIL & 11 \\
\hline SAMBA & 08 \\
\hline OUTROS: RAP; REGGAE; FUNK & 02 \\
\hline
\end{tabular}

Quadro D: Música popular brasileira

Dentre os grupos, cantores e compositores estrangeiros destacaramse sempre em ordem decrescente: Iron Maiden, Metallica, Green Day, Never Shout Never, Paramore, Beatles, Nirvana, Bom Jovi, Avril Lavigne, Ramones, Oasis, Panic At The Disco, dentre outros. Pode-se observar a predominância do gênero rock em suas diversas vertentes.

\begin{tabular}{|c|c|}
\hline (ANGLO-AMERICANOS) & QUANTIDADE \\
\hline IRON MAIDEN (HEAVY METAL) & 19 \\
\hline METALLICA (HARD CORE) & 10 \\
\hline GREEN DAY (PUNK ROCK) & 09 \\
\hline NEVER SHOUT NEVER (FOLK ROCK) & 08 \\
\hline PARAMORE (ROCK) & 07 \\
\hline BEATLES (ROCK) NIRVANA (ROCK) & 06 \\
\hline $\begin{array}{c}\text { BON JOVI (ROCK) AVRIL LAVIGNE } \\
\text { (POP PUNK) }\end{array}$ & 05 \\
\hline $\begin{array}{l}\text { RAMONES (PUNK ROCK) OASIS } \\
\text { (ROCK) PANIC AT THE DISCO } \\
\text { (ROCK) }\end{array}$ & 04 \\
\hline
\end{tabular}

Quadro E: Grupos, cantores e compositores estrangeiros.

Dentre os grupos, cantores e compositores brasileiros, destacam-se Legião Urbana com uma grande incidência, CPM22, Detonautas, Charlie Brown Jr, Exaltasamba, Capital Inicial, Vítor e Léo, Strik, Cássia Eller, Titãs, Fernando 
e Sorocaba, Raul Seixas, Cazuza, Pitty, Chico Buarque e Caetano Veloso. Podese observar o predomínio do Rock Brasil, convivendo com o sertanejo e o pagode, e com muito pouca incidência da MPB.

\begin{tabular}{|c|c|}
\hline MÚSICA BRASILEIRA & QUANTIDADE \\
\hline LEGIÃO URBANA (ROCK) & 49 \\
\hline CPM22 (ROCK) & 28 \\
\hline DETONAUTAS (ROCK) & 17 \\
\hline CHARLIE BROWN JR. (ROCK) & 11 \\
\hline EXALTASAMBA (PAGODE) & 10 \\
\hline CAPITAL INICIAL (ROCK) & 06 \\
\hline VÍTOR E LÉO (SERTANEJO) & 05 \\
\hline STRIK (ROCK) & 05 \\
\hline CÁSSIA ELLER & 04 \\
\hline TITÃS (ROCK) & 04 \\
\hline FERNANDO E SOROCABA & 04 \\
\hline (SERTANEJO) & 03 \\
\hline RAUL SEIXAS (ROCK) & 03 \\
\hline CAZUZA (ROCK) & 03 \\
\hline RAIMUNDOS (ROCK) & 03 \\
\hline PITTY (ROCK) & 02 \\
\hline CHICO BUARQUE & 02 \\
\hline CAETANO VELOSO &
\end{tabular}

\section{Quadro F: Grupos, cantores e compositores brasileiros}

Com base nessa investigação dos interesses musicais, foi orientado aos estagiários que escolhessem juntamente com os alunos algumas músicas que pudessem ser trabalhadas na aula de História. A partir dessas escolhas foram selecionadas as seguintes canções: Índios, do grupo Legião Urbana, em 02 turmas do segundo ano, e 01 turma do primeiro; do mesmo grupo, a música Que país é este, foi trabalhada em uma turma do segundo ano; a canção $E u$ Nasci Há Dez Mil Anos Atrás, de autoria de Raul Seixas e Paulo Coelho, foi a escolhida em duas turmas, uma do primeiro e outra do segundo; e a música Rasputin, do grupo finlandês Turisas, foi aplicada em duas turmas do terceiro ano. Pode-se constatar que as músicas selecionadas para o trabalho em sala de aula, emergiram e estavam em consonância com os interesses e gostos 
musicais dos jovens alunos investigados; a intervenção dos investigadores foi no sentido de vislumbrar as potencialidades da fonte-canção para o trabalho em sala de aula, e possibilitar o cotejamento e comparação de uma mesma música em experiências e turmas diferentes.

Dentre as várias canções trabalhadas, selecionou-se uma, Eu Nasci Há Dez Mil Anos Atrás, que foi trabalhada pela aluna Luiza em uma turma do primeiro ano, e pela aluna Lígia em uma turma do segundo ano, sob perspectivas de abordagem diferentes. A partir de inferências à letra e à música da canção e da análise das protonarrativas da canção escritas pelos alunos, estabeleceu-se os seguintes recortes temáticos: para a aula da aluna Luiza, Religiosidades: Judaísmo, Cristianismo e Islamismo, a três religiões monoteístas; e para a aula da aluna Lígia, Fonte histórica e aprendizagem histórica: fontes históricas e fontes ficcionais. Pode-se verificar que em um recorte a abordagem foi de conceitos históricos ou conceitos substantivos; no outro recorte, a abordagem foi de categorias históricas ou conceitos de segunda ordem.

\section{Resultados}

O objetivo desse tópico é apresentar uma breve descrição e fazer uma comparação entre as duas experiências de trabalho com a canção delimitada: os estágios das alunas Luiza no primeiro ano e Lígia no segundo.

\section{Luiza do primeiro ano: as religiões monoteístas}

Em relação aos interesses e gostos musicais específicos da turma de primeiro ano do ensino médio, constituída por 30 alunos, 21 meninas e 09 meninos, com média de idade de 15 anos, dentre os diversos gêneros, grupos e cantores, predominou o gosto pelo rock equilibrado por aqueles que se autoidentificam como ecléticos; destaque para os grupos Legião Urbana e Never Shout Never, segundo a citação dos alunos. Depois do primeiro contato de 
investigação dos interesses e gostos musicais e da escolha da canção, o próximo passo foi a elaboração de um instrumento de investigação das protonarrativas da canção, escritas pelos jovens alunos a partir de uma primeira leitura e escuta da canção. A aluna estagiária investigadora elaborou a seguinte atividade: Após ouvir a música e ver o clipe da música Eu nasci há dez mil anos atrás e tendo como base o que ouviu e viu escreva uma narrativa histórica sobre um tema religioso, baseando-se na música.

Em uma amostra de 25 alunos, 14 fizeram inferências a Jesus, 04 a Moisés, e outros 04 a Arca de Noé, 02 alunos se referiram a bruxas queimadas e 01 citou umbanda e outro Davi, todos personagens expressos na canção selecionada. Diante da predominância do tema do cristianismo, o recorte temático da proposta de intervenção pedagógica foi trabalhar as três religiões monoteístas em suas semelhanças e diferenças históricas. O próximo passo foi a elaboração do Plano de Aula; os objetivos da aula delimitados pela aluna foram: "trabalhar a música como uma fonte histórica; mostrar as origens de cada religião monoteísta; e explicitar os pontos em comum entre elas". Os conteúdos delimitados foram Judaísmo, Cristianismo e Islamismo.

Os resultados da categorização das protonarrativas foram apresentados aos alunos, procurando-se contextualizar a fonte musical com uma biografia dos autores, além de estabelecer relações entre as protonarrativas e o recorte delimitado da aula: a três religiões monoteístas - judaísmo, cristianismo e islamismo. Em seguida, foram mostradas imagens na TV pen-drive e em materiais impressos, imagens de igrejas, sinagogas e mesquitas existentes na cidade de Curitiba, que foram reconhecidas por grande parte dos alunos. Simultaneamente, a aluna estagiária apresentou sua narrativa sobre a temática das três religiões, encaminhando uma atividade de análise de fontes primárias, constituídas por três fragmentos do Torá, Bíblia e Corão. O enunciado da atividade foi o seguinte: Indique os pontos, palavras e ideias em comum que você encontrou nos textos. Isto tem relação com a maneira de cada religião (como acreditar em Deus único e como ele 
é)? Explique. Uma atividade de avaliação e metacognição foram realizadas posteriormente, aplicada a 27 alunos participantes e continha as seguintes questões elaboradas pela aluna estagiária: O que aprendeu? O que já sabia sobre o tema? O que mais gostou de aprender? 0 que gostaria de saber mais sobre o assunto? Gostou do tipo de aula? Justifique. Teve dificuldades para realizar alguma das tarefas? Quais? Justifique.

Em relação à atividade com fragmentos do Torá, Bíblia e Alcorão, obteve-se a seguinte categorização de respostas: 25 alunos fizeram menção à expressão "Deus misericordioso"; 17 a "Deus único"; 12 menções a "proteção aos fiéis"; 03 inferências a "igualdade entre as três religiões"; e 01 para a "superioridade de Deus" e outra ao referir-se a Jesus como um "homem normal".

Por fim, em relação à atividade de avaliação e metacognição, destacamse: 0 que aprendeu? Religião: "sobre as três religiões monoteístas: cristianismo, judaísmo e islamismo"; "sobre a diversidade das religiões e o que há de comum entre elas"; "sobre algumas religiões e as formas que as pessoas se comportam dentro dela e suas crenças". Música: "aprendi a pensar que música também é história"; "aprendi a estudar história utilizando música"; "algumas músicas trazem em sua letra traços históricos do passado, religiões. Cultura: "nas atividades aprendi um pouco mais sobre outras culturas que não tinha contato". O que mais gostou de aprender? Religião: "gostei de aprender sobre as religiões. É sempre bom saber mais sobre coisas que não temos tanta ligação, mas que estão tão perto"; "sobre as outras religiões, seus rituais e suas principais características". Temas históricos: "sobre as histórias do passado trazida e revelada na música "eu nasci a dez mil anos atrás". Música: "sobre as músicas que ela trabalhou em sala"; "que podemos utilizar a música como recurso de aprendizagem"; "que música velha também tem sentido". Gostou do tipo de aula? Justifique. Sim: A maioria dos alunos manifestou ter gostado da aula ministrada pela estagiária: "as aulas mais dinâmicas envolvem os adolescentes"; "é mais divertido e fácil de aprender"; "Sim, porque não é uma forma chata, tinha musicas"; "Foi uma maneira de 
quebrarmos a rotina da sala de aula conseguimos adquirir mais conhecimento"; "Principalmente com a utilização de vídeos e músicas"; "Porque houve mais interatividade do professor com ao aluno"; "porque é sempre importante aprender sobre outros assuntos e ampliar nossos horizontes"; "é diferente e mais interessante e da um pouco mais de curiosidades para quere aprende". Parcialmente sim: "sim, mas acho que deveria ser um pouco mais dinâmicas"; "sim, pois as aulas não nos prenderam apenas a textos e copiar"; "um pouco, pois mesmo utilizando a música não foi "incluído em nosso dia-a-dia"; "Poderia haver um pouco mais de dinâmica além disso poderíamos discutir sobre o assunto em grupos porém foi bom". Não: poucos alunos desaprovaram a aula ministrada pela aluna estagiária: "Não, deveria ser mais dinâmica, vídeos, slides etc..."; "Não muito, sempre a mesma musica, muitos textos e pouco dinâmica"; "não dava pra entender direito".Teve dificuldades para realizar alguma das tarefas? Quais? Justifique. Não: a maioria alunos não manifestou dificuldades em realizar as atividades propostas: "Não, pois todas eram sobre temas conhecidos dentro das religiões, se não fosse tão conhecidas havia os textos para ajudar"; "Não. Pois a maioria das questões eram questões pessoais". Sim: uma minoria expressou as dificuldades encontradas: "Sim, muitas vezes passavam as tarefas e não explicavam. Ela fala muito baixo!"; "Sim todos, ela fala muito baixo e não consegue explicar bem, fora que as atividades tem muito texto"; "Sim, quase todas, porque não consegui escutar a música, e dificuldade em entender o que foi pedido".

Lígia do segundo ano: fontes históricas e fontes ficcionais

A segunda aluna realizou o seu estágio em turma do segundo ano do Ensino Médio, constituída inicialmente por 25 alunos, sem especificação de gênero, com idades variando entre 14 e 16 anos. Em um primeiro contato por meio da investigação dos interesses e gostos musicais dos jovens alunos, constatou-se que a música é vista como entretenimento e o gênero preferido é o rock; o grupo mais citado foi novamente Legião Urbana. Em relação a uma 
questão surgida sobre os usos da música em uma aula de histórica, os alunos apontaram que a música somente poderia ser utilizada quando determinados conteúdos estivessem sendo trabalhados (o período de Ditadura Militar, principalmente) e ainda mencionaram ícones da música "engajada" como Chico Buarque e Caetano Veloso. Essa visão é condizente com a constatação de que muitos professores de história, no caso brasileiro, só usam músicas quando ministram determinados conteúdos e na maioria das vezes apenas como "ilustração" ou para "motivação" dos alunos.

A partir desse levantamento e das reflexões decorrentes, a turma escolheu a canção Eu Nasci Há Dez Mil Anos Atrás, e o próximo passo foi aplicar o instrumento de investigação das protonarrativas escritas pelos alunos a partir das leituras e escutas da canção selecionada. Após audição e leitura da letra da música, foi solicitado aos alunos que respondessem as seguintes questões: Você acha que apenas aqueles que viveram e testemunharam determinadas épocas podem falar de forma verdadeira sobre ela? $\mathrm{Na}$ sua opinião, conhecer as experiências do passado ajuda a compreender melhor o presente? Você acha que todos aqueles que viveram determinados acontecimentos do passado vão narrá-los da mesma forma? Por que? Você acha que é possível ter acesso e conhecer o passado, tem tê-lo vivido? De que forma?

Desta atividade participaram 18 alunos, sem especificação de gênero. Em relação à primeira pergunta, 14 alunos responderam não e 04 sim; desses últimos, 02 responderam que "somente quem vivenciou uma época pode contar como as coisas realmente aconteceram", e 01 aluno relatou: "No presente não se pode julgar o passado. Apenas as pessoas que viveram podem falar sobre ele". Já em relação às respostas negativas, 06 expressaram que "pode-se conhecer essas épocas por meio de registros deixados (fotos, registros escritos, livros e outros)"; 05 afirmaram que se conhece o passado "por meio do estudo"; 04 fizeram ressalvas quanto "as pessoas podem "inventar", "fantasiar", "aumentar" esses acontecimentos ou não falam a verdade"; 04 manifestaram que "as pessoas que viveram outras épocas podem 
ajudar a compreendê-la, mas não se pode usar somente isso para entender o passado". Em relação à segunda pergunta, 17 alunos responderam que sim e somente 01 disse que não; 08 alunos expressaram a ideia de "causa e conseqüência", uma relação causal entre o passado e o presente, revelando uma concepção um pouco mecanicista, relacionada a uma noção evolucionista do processo histórico associada implicitamente à ideia e ideal de progresso. Cerca de 06 alunos manifestaram que a experiência do passado "ajuda a compreender os acontecimentos atuais"; e 03 alunos manifestaram a ideia de que "as experiências do passado podem modificar o presente". A única resposta negativa diz que "não se pode conhecer presente, passado e futuro, embora seja interessante conhecer como as coisas aconteciam no passado". Em relação à terceira questão, o resultado foi totalmente oposto da questão anterior: 17 responderam que não, e somente 01 aluno respondeu que sim; esse respondeu que acha que todos que viveram determinados acontecimentos do passado vão narrá-los da mesma maneira, porque "os acontecimentos estão guardados na memória dessas pessoas". A grande maioria expressou que não, pois "cada um tem uma forma de ver o que aconteceu"; "as pessoas podiam ter interesses diferentes em uma mesma época", em uma clara referência ao multiperspectivismo; "cada um acrescenta algo a uma história, mesmo não sendo verdade", e "pode-se esquecer de algum detalhe", sempre em ordem decrescente de incidência de respostas. A última questão, relacionada ao acesso ao conhecimento do passado, os 19 alunos foram unânimes em afirmar que é possível ter acesso ao passado por meio de várias formas: fontes (fotos, artigos de jornais, revistas, filmes, livros da época, relatos, pintura, escultura, música, etc.); livros; estudo; internet; pessoas que viveram no passado; professores; arqueologia; entre outros.

A partir dessa categorização das protonarrativas da canção encaminhouse a elaboração do plano de aula com o seguinte recorte: fontes históricas e fontes ficcionais, centrado na análise de personagens históricos e ficcionais. 0 objetivo era orientar os alunos em relação à forma como abordar o passado presente nas fontes para a produção do conhecimento histórico e nesse 
sentido, procurar superar concepções equivocadas apresentadas pelos alunos (como a ideia de evolução em relação ao passado, muito presente nas narrativas desses jovens) e reforçar ideias como o acesso ao passado por meio da fonte histórica, mas com o intuito de orientá-los sobre o fato de que 0 passado não está na fonte, e sim que somente por meio do método histórico a fonte é transformada em história.

Dentre os objetivos específicos buscou-se, a partir da reflexão sobre o método da pesquisa histórica, levar os alunos a elaborar questões para abordar as fontes; retomar a categorização feita das ideias prévias dos alunos em aula anterior, retomar a música apresentada articulando-a com a vida e a obra dos autores, as condições de criação e produção da canção e o contexto histórico em que foi produzida. Em suma, o percurso metodológico da aula constou da retomada das protonarrativas das canções escritas pelos alunos; contextualização da canção, seus autores, influências, qual a receptividade do álbum no período; problematização, juntamente com os alunos, de duas novas fontes-imagens, sob a perspectiva do método da pesquisa histórica; produção de narrativas por parte dos alunos nas atividades de avaliação e metacognição.

Lígia iniciou a sua aula retomando as questões das protonarrativas da canção, procurando problematizar junto aos alunos, mediada pela explanação de alguns pressupostos do método do historiador na produção do conhecimento histórico. Alguns alunos participaram de forma significativa no debate, expressando concepções de multiperspectividade: "cada um tem um ponto de vista" ou, há "vários pontos de vista". Em um segundo momento, foi retomada a canção Eu Nasci Há Dez Mil Anos Atrás. Depois de uma nova audição da música, contextualizou-se o ano de lançamento do disco homônimo na discografia de Raul Seixas, destacando o sucesso de vendas da sua parceria com Paulo Coelho naquele ano de 1976. Apresentou-se uma breve biografia do cantor e compositor baiano. A estagiária questionou os alunos sobre os personagens expressos na canção para articular com o próximo passo da sua aula; uma atividade com fontes imagéticas envolvendo dois personagens 
expressos e selecionados da canção: Conde Drácula e Adolf Hitler. Foi apresentada a atividade com fontes, por meio de material impresso e projetando na TV pen-drive duas imagens: a primeira, de um cartaz de propaganda da primeira adaptação da obra literária Drácula para o cinema em 1931; a segunda, a reprodução de uma fotografia que retrata um discurso de Adolf Hitler realizado em 1935. Procurou-se fazer um debate a partir da problematização das fontes, tomando como referências, questões como: Os alunos distinguem a natureza das fontes? No caso, eles levam em consideração que uma fonte é histórica e a outra ficcional? Abordagem da fonte: quando foi produzida (em que época? Não necessariamente o ano, mas verificar se os alunos conseguem localizá-las espaço-temporalmente), com que objetivo foi produzida? Por quem? Quem figura nas duas imagens? O que se pode apreender dela? Quem fotografou? Quando? Onde? Por quê? Como? Para quê? A quem se destina? Qual o conteúdo e a forma da imagem? Quais os significados atribuídos a ela? Procurou-se catalisar algumas dessas perguntas, sistematizar as respostas dos alunos e fazer a mediação com os pressupostos do método da pesquisa histórica, no sentido de distinguir as respectivas naturezas das fontes históricas e fontes ficcionais. Em seguida, solicitou-se aos alunos duas tarefas: Observe atentamente as duas imagens e elabore três perguntas para cada uma a partir dos seus interesses e curiosidades; Escreva narrativas sobre as imagens, procurando responder às questões que você elaborou.

Foi dado um tempo para que os alunos realizassem a tarefa ao responder as duas questões. Em seguida foi entregue a atividade de avaliação que consistiu nas seguintes perguntas: Quais as semelhanças e diferenças entre as duas fontes? Quais as diferenças e semelhanças entre as duas narrativas que você escreveu? Quais as diferenças e semelhanças entre a história e a literatura? Literatura e música podem ser usadas como fontes históricas para ter acesso ao passado? Como e por quê?

Depois dessa atividade, ainda foi entregue mais uma atividade, a tarefa de metacognição que consistiu em apenas dois enunciados: $\mathbf{O}$ que você 
aprendeu de significativo nessa aula de história a partir do uso da música? A partir de suas experiências nessa aula, elabore uma narrativa histórica ou a letra de uma música com o seguinte título: Eu NÃO nasci há 10 mil anos atrás, mas não tem nada nesse mundo que eu não possa saber um pouco mais.

Em relação à primeira atividade com as fontes, dentre as perguntas elaboradas pelos alunos para o cartaz do filme Drácula de 1931, destacam-se as que se preocupam em delimitar o "impacto do filme na época", "os significados presentes no cartaz", o período e o local de lançamento do filme. Quanto às narrativas produzidas pelos alunos a partir das suas próprias perguntas, 03 destacaram a "análise do impacto do filme no momento de seu lançamento", o significado do personagem Drácula naquele momento, e a "beleza do ator como apelo para assistir ao filme". Em relação à problematização da fotografia do discurso de Hitler de 1933, não distinguindo na categorização se foi pergunta ou narrativa, 04 alunos expressaram a "dominação em relação ao outro", 03 concentraram-se na análise da imagem de Hitler, e o restante entre "quem foi Hitler" e o poder e o temor do mesmo.

A atividade de avaliação apresentou os seguintes resultados para as quatro perguntas. Em relação à primeira pergunta, sobre as "semelhanças e diferenças entre as duas fontes", 06 alunos identificaram a diferença de "que uma é fictícia e a outra histórica"; 02 alunos sustentaram que "ambas podem ser usadas como fonte histórica"; 02 alunos identificaram a semelhança entre as duas imagens representarem "homens temidos"; 01 aluno apontou outra semelhança, "as duas são datadas", e outro aluno sustentou que "apenas uma música não é suficiente como fonte". A segunda pergunta sobre as diferenças e semelhanças entre as duas narrativas escritas pelos alunos, foi assim respondida: 03 alunos distinguiram que uma narrativa trata-se de "ficção" e a outra de "realidade"; outros 03 alunos trataram de diferentes assuntos como a "autoridade de Hitler", "o medo causado por Drácula", e de que "a mulher é símbolo de fragilidade em ambas abordagens". Em relação à terceira pergunta sobre "as semelhanças e diferenças entre História e Literatura", 04 alunos 
relacionaram História ao "real" e a Literatura ao "fictício"; 02 expressaram que "a literatura pode estar baseada em fontes históricas" e 01 que sustentou que o acesso ao passado se dá através da História. A última pergunta da avaliação, sobre se literatura e música podem ser usadas como fontes, 06 alunos escreveram que sim, pois constituem "expressões de um momento"; 03 alunos abordaram as questões do "estudo" e da "pesquisa"; e 02 alunos destacaram a perspectiva da "análise do contexto" de emergência e recepção das fontes em questão.

E para finalizar, a atividade de metacognição que foi respondida por 06 alunos, consistiu em perguntar sobre o que aluno aprendeu de significativo nessa aula, e solicitar que escrevessem uma narrativa histórica ou uma letra de música, a partir de um título sugerido. Em relação ao aprendido os alunos destacaram: a "utilização da música em aula de história", a "nova forma de aprendizado" e a constatação de que "música é fonte histórica". Nas narrativas ou letras de músicas escritas apareceram ideias tais como: "não é preciso viver um acontecimento para conhecê-lo"; "por meio das fontes pode-se ter acesso ao passado"; "com a tecnologia, o acesso ao passado é facilitado"; e "documentos datados são fontes".

\section{Considerações Finais}

Esse estudo exploratório veio corroborar outros estudos exploratórios e o estudo piloto que resultou no relatório de qualificação da tese que está sendo realizada no âmbito do Programa de Pós-Graduação da Universidade Federal do Paraná. Mais do que isto, sinalizou uma nova perspectiva metodológica que tem como pressuposto o gosto musical dos jovens alunos enquanto ponto de partida para os usos da canção na sala de aula. A canção popular urbana, produto e processo da indústria fonográfica cultural, faz parte da vida prática, está presente nos processos de escolarização e é um dos elementos significativos na constituição das múltiplas identidades juvenis. Incorporar a cultura na escola, a cultura juvenil como princípio estruturante da cultura 
histórica escolar, constitui uma perspectiva instigante para superar o criticado, mas ainda predominante, "ensino tradicional de história", e promover a expansão da aprendizagem na perspectiva da Educação Histórica.

A canção popular apropriada enquanto fonte histórica, ou em outras palavras, a fonte canção pode ser significativa nos processos de ensino e aprendizagem histórica e na subjacente constituição, formação e progressão da consciência histórica de jovens alunos do ensino médio. No entanto, deve emergir dos interesses musicais dos sujeitos investigados, e não ser imposta pelos gostos musicais dos professores e pelas "ilustrações" dos manuais didáticos que, segundo pesquisas, privilegiam a MPB em suas relações com o período da ditadura militar brasileira (1964-1989). Apesar dessa visão já estar um pouco cristalizada na cultura histórica escolar, apesar de a MPB, como parte integrante da música popular brasileira, fazer parte dos gostos musicais dos jovens, a investigação sinalizou que o gênero preferido dos jovens alunos do ensino médio, com idades entre 14 e 17 anos, é o rock, seja ele estrangeiro ou nacional. Músicas do Iron Maiden ou da Legião Urbana estariam mais adequadas aos gostos musicais desses jovens alunos do ensino médio do que canções de Chico Buarque de Holanda e Caetano Veloso, presentes nos manuais didáticos brasileiros e hipoteticamente mais ao gosto dos professores. A escolha da canção de Raul Seixas emergiu desse processo e reflexão e pareceu sintetizar um caminho do meio entre as seleções dos professores e dos alunos, já que se trata de um cantor compositor da década de 1970 .

Trabalhar com música em sala de aula pressupõe uma literacia histórica, uma alfabetização histórica, teórica e metodológica de professores e alunos para o tratamento adequado à especificidade e complexidade da fonte canção, com vistas à escritura de narrativas da canção por parte dos alunos. As dimensões estéticas, cognitivas e políticas da cultura histórica presente em certas canções, potencializam o acesso ao passado que se faz presente na cultura juvenil. Certas canções potencializam as três dimensões da aprendizagem histórica: a experiência do passado, a interpretação do presente e a orientação do futuro. 
Pode-se concluir que a proposta do estudo exploratório Educação Histórica e cultura jovem: a música como fonte para o ensino e a aprendizagem histórica e a formação da consciência histórica de jovens alunos do ensino médio, atingiu os seus objetivos, assim como foi muito significativa e instigante do ponto de vista do aluno de Prática de Docência. Definiu e credenciou as disciplinas objeto de formação e especialização do doutorando: Prática de Ensino e Estágio Supervisionado em História e Metodologia do Ensino de História, com vistas à síntese em uma só disciplina, a Didática da História, entendida como ciência do ensino e da aprendizagem em história. Mais além, superou as expectativas ao provocar uma mudança consentida na rota de viagem da pesquisa e vislumbrar novos horizontes para a investigação sobre as leituras, escutas, falas e escrituras da canção popular no ensino de história, na perspectiva da Educação Histórica.

\section{Referências}

AZAMBUJA. L. Leitura, Canção e História: Mundo Livre s/a contra o Império do Mal. Florianópolis: Dissertação (Mestrado em Literatura). Programa de PósGraduação em Literatura, Universidade Federal de Santa Catarina, 2007.

BARCA, I.. Os jovens portugueses: ideias em História. In: Perspectiva: Revista do Centro de Ciências da Educação. Dossiê Juventude e Educação. Universidade Federal de Santa Catarina. v.22, n.2 Florianópolis: Editora da UFSC, 2004.

CAMACHO, L. M. Y. A invisibilidade da juventude na vida escolar. Perspectiva: Revista do Centro de Ciências da Educação. Dossiê Juventude e Educação. Universidade Federal de Santa Catarina. v.22, n.2 Florianópolis: Editora da UFSC, 2004.

DUBET, F. \& MARTUCCELLI, D. La experiencia liceísta. In: En la escuela. Sociologia de la experiencia escolar. Buenos Aires: Losada, 1997.

NAPOLITANO, M. História \& Música: história cultural da música popular. Belo Horizonte: Autêntica, 2002.

. Aquarela do Brasil. NETROVSKI, A. (Org.). Lendo música: 10 ensaios sobre 10 canções. São Paulo: Publifolha, 2007. 
RÜSEN, J. Razão Histórica. Teoria da história: os fundamentos da ciência histórica. Trad. de Estevão de Rezende Martins. Brasília: Editora Universidade de Brasília, 2001.

- Reconstrução do Passado. Teoria da história II: os princípios da pesquisa histórica. Trad. Asta-Rose Alcaide. Brasília: Editora Universidade de Brasília. 2007.

SCHMIDT, M. A., BARCA, I. (Org.). Aprender história: perspectivas da educação histórica. Ijuí: Ed. Unijuí, 2009.

Enviado pelos autores em 07 de Maio de 2012. Aprovado em 27 de Junho de 2012 